4. The treatment of syphilis is far more efficient than formerly and syphilis is the only one of the venereal diseases which appears to be declining both in prevalence and infectivity.

5. The blood picture in syphilis and sympathetic ophthalmitis is similar.

6. Is it possible that a syphilitic background makes true sympathetic ophthalmitis more possible?

It should be noted with interest that in 1887, Marcus Gunn strongly urged the use of mercury in sympathetic ophthalmitis.

Yours truly,

Melbourne,

JAMES W. BARRETT.

June 16, 1927.

\title{
KERATITIS DUE TO MUMPS
}

To the Editor of The British Journal of OphthalmologY

Sir,--In the British Journal of Ophthalmology, Detroit, of Lille, quotes a case of the above. Some years ago I saw a similar case, and there was no doubt as to the cause, the patient having had a typical attack of mumps which he caught from his sister. When I first saw him his vision was reduced to hand movements at two feet, and the cornea was completely clouded all over, no fundus reflex could be obtained, and there was considerable circum-corneal injection. The appearance was that of an interstitial keratitis with grey streaks radiating all over the cornea. The iris was not involved. The treatment was simply atropine drops, 1 per cent., and in the course of about a week the whole cornea cleared, and vision became normal.

These cases must be rare, as I remember writing to Sir Arnold Lawson at the time to ask him if he had ever seen a similar case, and my recollection is that he said he had not, and very kindly looked up the literature for me, with the result that he could only find I think five cases quoted and those by a French oculist, whose name I have forgotten. It is possible that he may remember the facts. In view of the case mentioned, I thought mine might be of interest.

H. Goodwyn.

NEWBURY,

BERKS. 